co-ordination of scientific effort. The recently published volume for 1938 (No. 23) includes in its 400 pages contributions by several leading Polish men of science. Thus, Prof. B. Kieskowski discusses the question whether philosophy can be considered as a science, and gives cogent reasons for an affirmative answer. Prof. W. Semkowicz has two lengthy contributions, the first being devoted to a comprehensive account of scientific and philological work at Cracow, the seat of the Polish Academy of Sciences and of the Jagellonian University, since the establishment of the republic. The second article is a survey of the special needs of science to-day. There is an informative description, by Dr. W. Siemaszko, of recent advances in phytopathology both in Poland and elsewhere. This branch of applied botany is of special significance to a country like Poland, which has a large agricultural industry as well as extensive forests. Particular attention is given to the organization and co-ordination of research, and reference is made to the facilities for planned researches in Poland, Czechoslovakia, Britain and America. Of immediate interest, too, is a contribution by Dr. J. Golabek on Polish cultural facilities in Czechoslovakia and the collaboration between men of science in these two Slav countries. A section devoted to reviews makes reference not only to books, but also includes résumés of articles that have appeared in scientific periodicals. This volume of Nauka Polska concludes with a bibliography of works dealing with the 'science of science' for the years 1935 and 1936.

\section{National Museum of Canada}

THE annual report for 1936-37 of the National Museum of Canada marks good progress, particularly in the resumption of field investigations. During the summer of 1936, field parties were engaged in biological work on the Pacific coast, ornithological investigations in Manitoba, a special biological survey of Thelon Game Sanctuary, botanical surveys in Ontario and the Arctic, archæological excavations in Ontario and the Arctic, anthropological studies of French-Canadian art and handicrafts, and the effect of the contact of the white man upon Indian culture. As a result, much material has been added to the collections and scientific information of value has been obtained. To the naturalist, one of the most interesting investigations is that mentioned in Dr. R. M. Anderson's report on the work of the Biological Division. A survey is being made of the region about Horseshoe Lake, which was burned over about a hundred years ago and now shows the conditions that follow natural reforestation in British Columbia. Now these blocks of second-growth timber are acting as reservoirs of wild life, islands of refuge in the midst of a country which had been burned so that all small wild life was destroyed. For long stretches the burnt area showed no trace of a mammal, and the destruction of mossy ground, cover and rotten logs removed such as weasels, shrews, snakes, frogs and slugs. From the protection of the natural refuges the fauna is beginning to recolonize the burnt-out regions.

\section{A Century of Sociology}

IN the R. R. Kale Memorial Lecture 1938 to the Gokhale Institute of Politics and Economics, Prof. C. S. Ghurye reviewed the social process in the light of a century of sociology. Social process, he considers, has two aspects : the nature of cultural development as reflected in the trend of thought about man as a living entity, and the process by which the individual is assimilated into the cultural flow of the times. Although Protagoras gave effective currency to one of the fundamental requisites of science-to take experience as the only category strictly knowable for the human intellect-the ethical outlook afterwards overshadowed or eliminated the scientific spirit, and Prof. Ghurye considers that it was not until Montesquieu that human experience was again viewed with the eye of a man of science. In his argument, the force of human motives first received real recognition. Stressing the significance of the English contribution to the advancement of knowledge on the Comtian plane, he pointed out that the social life of man is becoming the centre of attraction and motivation the principle of explanation. The psychology of motivation found its scientific liberator in Shand, who sought the explanation of human motivation in the social behaviour of man and not in his biological activity.

Screntifically, the proper planning of a good life must rest on the understanding of life, and the psychological study of the individual and society should precede the study of man as a political and a moral being. In conclusion, Prof. Ghurye, discussing the institution of marriage, urged that in view of the importance of the first few years of the individual's life in the social process, if accommodation of the individual into his social mould was to be smooth and harmonious, the environment in those years must be provided by a small group, the individual constituents of which are highly sympathetic. Such a group is only ideally provided in the family unit. Prof. Ghurye made an earnest plea for the institution of a chair of sociology in the Gokhale Institute.

\section{Photographic Reproduction of Documents}

AN exhibition is being held at the Science Museum, South Kensington, of many types of apparatus for the photographic reproduction of documents, suited to both occasional and extensive use, and adapted to varied requirements. It comprises several original types of cameras and projectors, suitable for amateur and professional use. Some of the apparatus is arranged to utilize standard commercial general utility miniature cameras. Other cameras shown are designed specifically for the purpose of book-reproduction-in whole or in part-in reference libraries, together with the corresponding projecting apparatus for magnifying the film images to enable natural size or enlarged images to be viewed or prints to be made. Finally, there are exhibits illustrating the use of photographic apparatus specially designed to provide at cheap rates both single and multiple copies of documents without reduction of their natural sizes. The exhibition, which has been arranged in con- 